\title{
An Atlas on Cephalometric Landmarks
}

\section{Basavaraj Subhashchandra Phulari}

Publisher: Jaypee Brothers Medical

Publishers (P) Ltd

Language: English

ISBN: 978-93-5090-324-7

Edition: 1/e

Publish Year: 2013

Pages: 230, illustrated

Price: $£ 68.00$

Cephalometry is used for diagnosis, treatment planning, monitoring and evaluation of the treatment, craniofacial growth and development. The application fields are orthodontics and dental facial orthopedics and recently complex oral rehabilitation.

This book gives detailed explanations on how to achieve the correct positioning of cephalometric landmarks to obtain a correct cephalometric analysis.

The book has 20 chapters divided into 11 separate sections.

After a brief introduction to the history of cephalometry in orthodontics, it presents the classification of the different types of cephalometric landmarks. The following chapters make a minute presentation of each point of the head - cranial bones, facial bones and

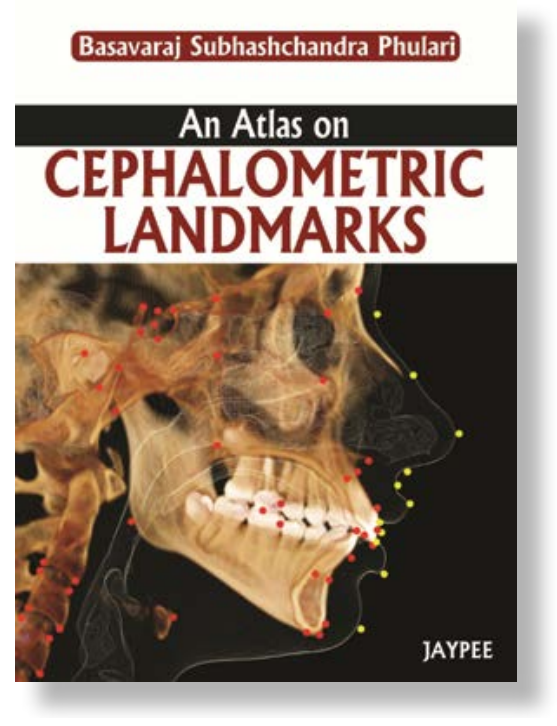

dentition, soft tissue, bones and cervical pharynx. The final chapters discuss different types of imaging used to trace cephalometric landmarks and their applications and also compare radiological imaging techniques.

The book includes more than 350 color images and illustrations and is very useful both for orthodontists, and prosthodontists who practice complex oral rehabilitation.

https://doi.org/10.25241/stomaeduj.2015.2(2).bookreview.4

Florin Eugen

Constantinescu

DDS, PhDStudent

ROPOSTURO

Holistic Dental Medicine Institute

Bucharest, Romania

E-mail:

dr.florin.constantinescu@gmail.com

The Book Review is drafted in the reviwer's sole wording and illustrates his opinions. 